\title{
The first known use of the double-orifice valve technique for Ebstein anomaly, performed 30 years ago
}

\author{
Eva Maria Delmo Walter, MD, MSc, PhD, Mariano Francisco del Maria Javier, MD, and \\ Roland Hetzer, MD, PhD, Berlin, Germany
}

\author{
From the Department of Cardiothoracic and Vascular Surgery Cardio Centrum Berlin, Berlin, Germany. \\ Disclosures: Authors have nothing to disclose with regard to commercial support. \\ Received for publication Sept 17, 2018; revisions received Oct 14, 2018; accepted for publication Oct 17, 2018; \\ available ahead of print Nov 27, 2018. \\ Address for reprints: Eva Maria Delmo Walter, MD, PhD, MSc, Department of Cardiothoracic and Vascular Sur- \\ gery, Cardio Centrum Berlin, Berlin, Germany Unter den Linden 21 10117, Berlin, Germany (E-mail: eva. \\ delmowalter@gmail.com). \\ J Thorac Cardiovasc Surg 2019;157:e47-9 \\ $0022-5223 / \$ 36.00$ \\ Copyright (c) 2018 by The American Association for Thoracic Surgery \\ https://doi.org/10.1016/j.jtcvs.2018.10.077
}

More than a century and a half has passed since the complex congenital defect of the triscupid valve (TV) was described in 1866 by the German pathologist Wilhelm Ebstein. ${ }^{1}$ The variably deformed septal or posterior leaflets are displaced downward into the right ventricle (RV), dividing it into a proximal atrialized and distal ventricularized (true or functional ventricle) chambers. These, in addition to annular dilatation, result in varying degrees of TV incompetence. The abnormalities in structure and function of the RV, and less commonly of the left ventricle (LV), are consequently exacerbated. Because of the diverse pathologic presentations, numerous anatomic and functional techniques $^{2,3}$ have evolved in an attempt to correct the TV incompetence. We describe here the first known use of the double-orifice technique for Ebstein anomaly and discuss the 30-year follow-up.

\section{CASE REPORT}

A 41-year old woman with a diagnosis of type C Ebstein anomaly (restricted motion of the anterior leaflet, which adheres to the RV wall endocardium by fibrous bands or abnormal chordae tendineae) with concomitant atrial septal defect and persistent left superior vena cava underwent surgery for severe TV incompetence. Intraoperative findings were cardiomegaly, a huge right atrium, a diminutive $\mathrm{RV}$, a dilated $\mathrm{LV}$, and a severely deformed TV. Under cardiopulmonary bypass, intermittent cardioplegia administration, and moderate systemic hypothermia, exposure of the right atrium revealed an atrial septal defect, which was closed directly. The TV was severely deformed. The enormously enlarged anterior leaflet was completely split at the middle by a cleft. The chordae adherent to the anterior RV wall (Figure 1, A) were subsequently dissected off. The rudimentary septal leaflet was displaced apically, creating a large atrialized chamber. Several techniques for TV reconstruction or

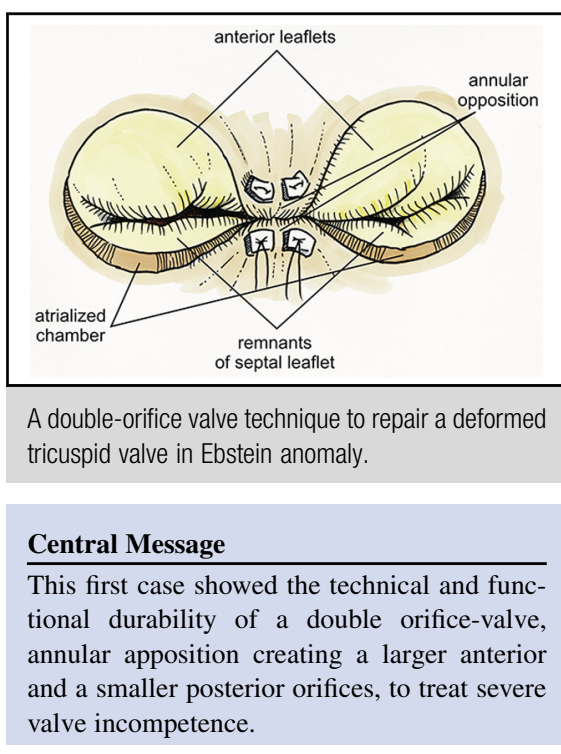

See Editorial Commentary page e51.

remodeling (obliteration of the atrialized chamber, annuloplasty, and annular shortening) were attempted without obtaining valve competence. Thereafter, two 3-0 polypropylene mattress sutures with autologous pericardial pledgets were passed through the midportion of the true anterior annulus onto the opposite corresponding point in the natural annulus above the septal leaflet (Figure 1, $B$ and $C$ ), and then tied. Approximation of the anterior annulus to the opposite natural annulus created a valve with 2 orifices and enabled valve closure by coaptation of the 2 solid parts of the anterior leaflet onto the septum of the atrialized chamber (Figure 2). The anterior orifice measured $23 \mathrm{~mm}$, and the posterior orifice measured $15 \mathrm{~mm}$. Transvalvular saline solution instillation revealed a competent TV which was confirmed by an intraoperative transesophageal echocardiography. On aortic clamp removal, atrial fibrillation occurred, which initially responded to defibrillation but developed into an intermittent atrioventricular block III. An epicardial pacemaker system was implanted in the RV, with the generator placed in the rectus fascia and additional temporary electrodes placed in the right atrium and RV. A longer reperfusion time was necessary to wean the patient from cardiopulmonary bypass. Ischemic time was 58 minutes, and total bypass time (including reperfusion time) was 190 minutes. The 

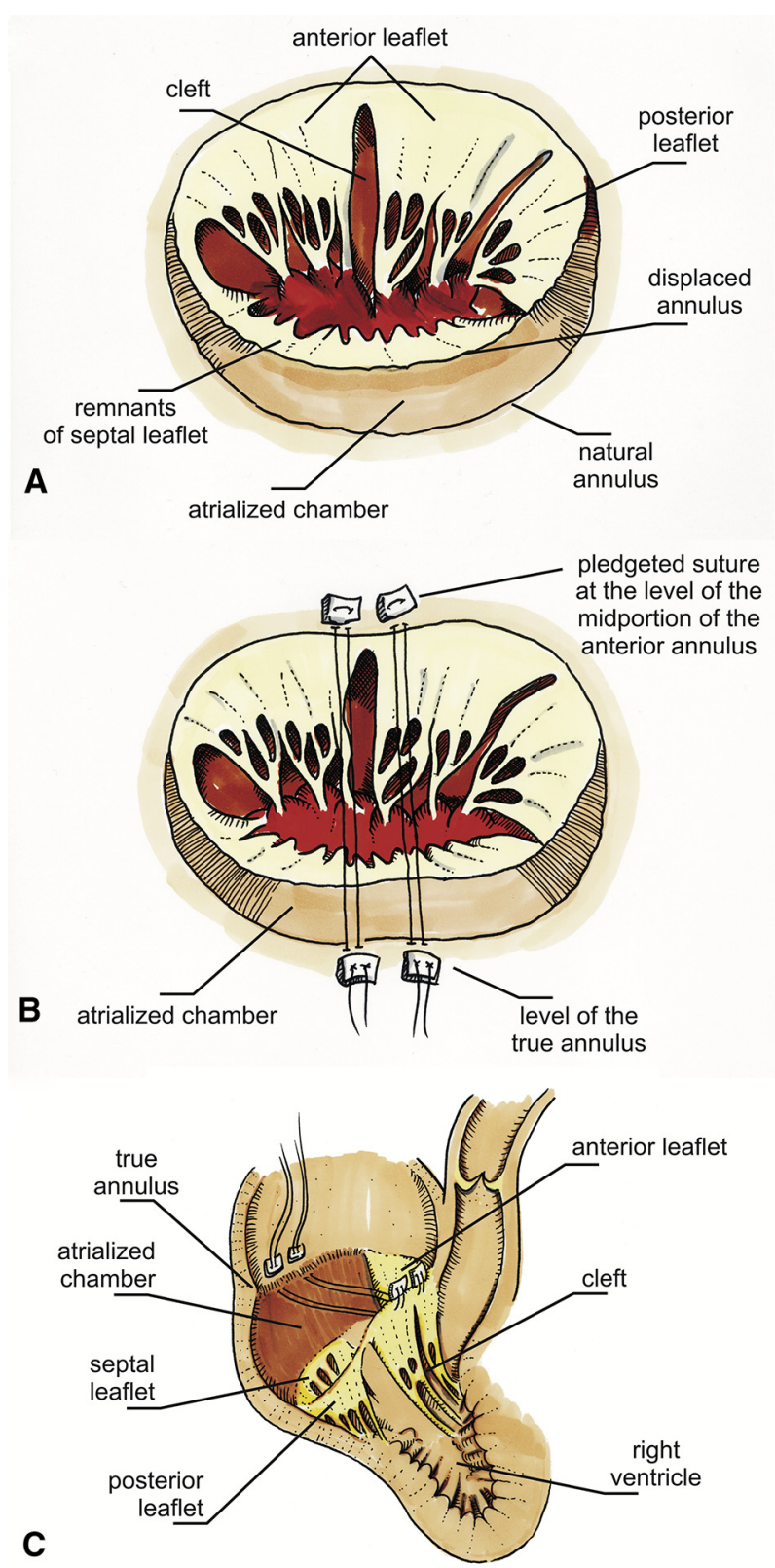

FIGURE 1. Illustration showing (A) a severely deformed tricuspid valve with the enormously enlarged anterior leaflet, split by a cleft in the middle, with chordae much adherent to the anterior right ventricular wall. The remnants of the septal leaflet are far displaced toward the apex, leaving a large atrialized chamber between itself and above the natural annulus. B, Two 3-0 polypropylene mattress sutures supported with autologous pericardial pledgets were passed through the middle portion of the anterior annulus onto the natural annulus above the atrialized chamber. C, Lateral view showing the annular sutures between anterior and natural annulus above the atrialized chamber.

postoperative course was unremarkable, and the patient was discharged 5 days later.

Serial follow-up echocardiography for the first 20 postoperative years showed absence of TV incompetence. TV

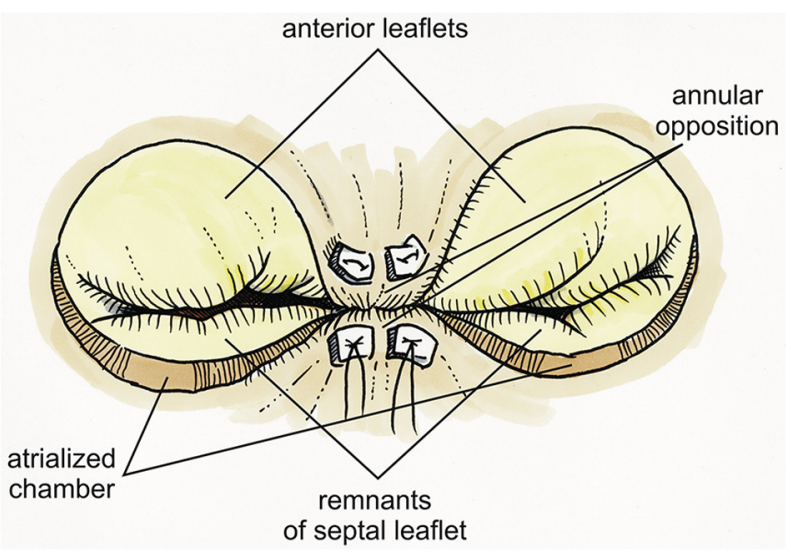

FIGURE 2. Approximation of the anterior annulus onto the opposite annulus created a valve with 2 orifices and enabled valve closure by coaptation of the 2 solid parts of the anterior leaflets and the septum of the atrialized chamber. The diameter of the anterior valve orifice measured $23 \mathrm{~mm}$, and the posterior orifice was $15 \mathrm{~mm}$.

incompetence developed after that point but was trivial to minimal without any inflow gradient in the last 10 years and deemed not progressive at the latest follow-up (a month before this report was written). Other findings in the latest transthoracic echocardiography include mild pulmonary and mitral valve insufficiencies and a competent aortic valve. The RV was seen to be hypertrophied, with mildly reduced ventricular function but without abnormal wall motion. The LV was normal in dimensions with good ventricular function. The $\mathrm{RV}$ and LV outflow tracts were both unobstructed. The pacemaker generator implanted 30 years ago has since been changed four times. The atrioventricular block resolved; however, the patient had a chronic atrial fibrillation develop. The pacemaker was therefore programmed to a ventricular pace/ sense mode. The patient's functional capacity (New York HeartAssociation functional class II) remained stable. She has no remarkable physical complaints and continues to engage in heart-conditioning exercises.

\section{DISCUSSION}

The surgery was performed thirty years ago. The patient is now 72 years old, living comfortably with a competent TV without repeat surgery. This first case showed us the durability of a simple repair to create a double-orifice valve to treat severe TV incompetence.

The basic principle aims to reduce the distance between the coapting leaflets such that the most mobile leaflet, usually the anterior, can coapt well to the opposite leaflet, ensuring valve closure by creating two orifices. With time, ${ }^{4,5}$ we refined the repair by gently placing pledgeted mattress sutures from the middle of the true anterior annulus to a spot on the opposite septal annulus approximately two-thirds of its length, as measured from the anteroseptal commissure, to avoid injury to the bundle 
of His. Prudence has been exercised not to place the sutures too deep to avoid injury to the right coronary artery or kinking or narrowing.

\section{References}

1. Ebstein W. Ueber einen sehr seltenen Fall von Insuffizienz der Valvula tricuspidalis, bedingt durch eine angeborene hochgradige Missbildung derselben. [About a very rare case of insufficiency of the tricuspid valve, due to a congenital highgrade deformity of the same]. Arch Anat Physiol Wiss Med. 1866;238-54.
2. Hardy KL, Roe BB. Ebstein's anomaly: further experiences with definitive repair J Thorac Cardiovasc Surg. 1969:58:553-9.

3. da Silva JP, Baumgratz FJ, da Fonseca L, Franchi SM, Lopes LM, Tavares GM, et al. The cone reconstruction of the tricuspid valve in Ebstein's anomaly. The operation: early and midterm results. J Thorac Cardiovasc Surg. 2007;133: $215-23$.

4. Hetzer R, Hacke P, Javier M, Miera O, Schmitt K, Weng Y, et al. The long-term impact of various techniques for tricuspid repair in Ebstein's anomaly. J Thorac Cardiovasc Surg. 2015;150:1212-9.

5. Hetzer R, Javier M, Delmo Walter EM. The double-orifice valve technique to treat tricuspid valve incompetence. J Heart Valve Dis. 2016;25:66-71. 